\title{
Romanticized Abusive Behavior by Media Narrative Analysis on Portrayal of Intimate Partner Violence Romanticism in Korean Drama
}

\author{
Priscila Asoka Kenasri; Lidwina Mutia Sadasri* \\ Communication Science Department, Universitas Gadjah Mada, Indonesia \\ Corresponding Author: lidwina.mutia@ugm.ac.id
}

\begin{abstract}
Intimate relationships are often depicted in terms of a beautiful idealism, especially in mass media. However, evidence has shown that a vast number of women in such relationships are subjected to physical, emotional, and/ or sexual violence by their partner. Media plays an important part in shaping and reflecting social life, resulting in audience consumption of romanticized abusive behavior. Its audiovisual content can perpetuate the point of view that some violence is normal — or even romantic. Such a point of view can be found in Korean dramas, which have been popular among Indonesians for some 20 years, and do not show any signs of a decline in popularity. This study aimed to reveal a narration of the portrayal of intimate partner violence as romance in the Korean drama, The Heirs (2013). A qualitative method was used, drawing on Propp's seven spheres and Greimas' actantial narrative analysis model. The results showed how The Heirs projects romantic imagery masking abusive traits by establishing the main male character as a subject who forces a relationship without accepting rejection. Moreover, this study found that the romanticization of abuse was amplified by the depiction of the female protagonist as an object expressing her objection to giving her male counterparts the "thrill of the chase." These findings are ultimately consistent with the concept of romanticized media, particularly in portraying the romanticization of intimate partner violence.
\end{abstract}

Keywords: abusive behavior; intimate partner violence; Korean drama; media; narrative analysis; romanticization

\section{INTRODUCTION}

Intimate relationships are often portrayed in terms of a beautiful idealism. However, the evidence shows almost one out of three women in the world who have ever been in an intimate relationship have also been subjected to physical, emotional, and/or sexual violence by their romantic partner (WHO, 2012). Nations in Asia are not excluded from the prevalence of intimate partner violence across the world. The estimated number of intimate partner violence in the South Asia WHO region reached 37.7\%, a high number compared to other areas (WHO, 2017). If finds that in South Korea, which is included in this grouping, $71.7 \%$ of female respondents have experienced "being controlled" by an intimate male partner, $36.6 \%$ psychological/emotional abuse, $22.4 \%$ physical violence, and $37.9 \%$ sexual harassment (Hong, Yeon, \& Ju, 2015). Various explanations have been advanced to understand the prevalence of this abuse, with some researchers focusing on the role of the media.

Media, as a form of mass communication, has a role in conveying messages including, information and entertainment. One of its forms is audiovisual media which serves as a medium for cultural experiences 
(McQuail, 2010) and social themes such as romance. However, the portrayal of romance in audiovisual content are not always pleasing. Film and television programs commonly rely on exaggerated and unrealistic reports of romantic and sexual relationships to attract an audience (Johnson \& Holmes, 2009, p. 352). Research by Segrin \& Nabi (2002), Bachen \& Illouz (1996), and Holmes (2007) claim there is a relationship between romancethemed audiovisual content and the audience's romantic idealism. People's direct and indirect experiences shape their knowledge and cultural norms regarding relationships, including stereotypical portrayals in its various forms in mass media (Bachen \& Illouz, 1996; Cohen \& Weimann, 2000; Segrin \& Nabi, 2002 in Jin \& Kim, 2015, p. 51). Social culture is reflected in mass media content production, which is then consumed by the audience, thus perpetuating abusive traits in intimate partner violence as something unremarkable - even romantic - instead of a abuse.

One of the forms of audiovisual content that acts as a medium for romantic idealism is Korean drama. Other Asian countries have embraced media and popular culture from South Korea. Indonesians can relate to South Korean culture due to its cultural proximity (Iwabuchi, 2001 in Ariffin, Bakar, \& Yusof, 2018, p. 11). In Indonesia, South Korean audiovisual content has increased audience numbers (CNN, 2018). This trend is attributable to Korean drama's appeal with its attractive genre and storyline. The most popular Korean drama genre is the romantic genre, which has characteristics of melodrama with idealism such as "love at first sight," "happy ending," "pure love," and "true love" (Jin \& Kim, 2015, p. 53). The portrayal of an event within a romantic relationship can be distorted because romanticized media casts types of intimate partner violence in a romantic light.

In this paper the term "romanticized media" refers to an unrealistic or idealized depiction of a romantic relationship to appear more appealing than reality stemming from media influences (Segrin \& Nabi, 2002, p.260). The concept of romanticized media in this study is derived explicitly from the romanticization of abuse in the media.

Romanticization is defined as "talking or thinking about things in a way that makes them seem more romantic or attractive than they are" (Salmi, 2014, p. $10)$. The tendency of violent behavior by the male lead upon the female in an intimate relationship is commonly romanticized in various forms of popular media.

Romance is a word derived from the French word "romans" which means "story" and has been defined as an intimate relationship or feeling of passionate love between a couple. On the other hand, the word 'romance' means the opposite of reality, perpetuating unrealistic expectations (Galician, 2004, p. 13). Meanwhile, "romantic study" refers to the nature of a thing, such as content or behavior, that idealizes love and romance.

Romanticism is a state or quality filled with romantic ideas or feelings. In this study, the definition of romanticism used is an ideology that prioritizes love as the basis for determining a partner, love at first sight, only love, true love forever, and a destined partner against all odds (Sprecher \& Metts, 1989, in Jin \& Kim, 2015).

To explore the romanticization of abuse by the media it is necessary to explain that abuse or violence is the deliberate use of force, whether in the form of threats or actual force, against oneself, other people, or against a group, which causes injury, death, psychological harm, impaired development, or deprivation (WHO, nd). According to the World Health Organization, types of violence include, interpersonal violence such as intimate partner violence. Intimate partner violence (IPV) is violence in the context of a personal relationship that causes physical, psychological, or sexual harm as such a partner exerts power or control over his partner (National Criminal Justice Reference Service, 2018 \& WHO, 2012). The definition of an intimate partner in this study is "a partner in a close personal relationship. Intimate partner can be characterized by emotional connection; regular contact; persistent physical contact and or sexual behavior; identity as a partner and a familiar relationship and knowledge of each other's lives" (European Institute for Gender Equality, 2016, p. 3).

The romanticization of violence includes romantic images to depict controlling behavior and subtle depictions of differences in power (Béres, 1999, p. 192). Types of intimate partner violence researched in this study are physical aggression, sexual coercion, psychological/ emotional abuse, and controlling behaviors. The Heirs (2013) is believed to contain scenes and behaviors matching the definition of intimate partner violence.

The Korean drama studied in this writing is The Heirs (2013), produced by Choi Moon-suk, written by prominent scriptwriter Kim Eun-sook who also wrote the hits dramas Descendants of The Sun (2016) and Goblin (2017), and starring Hallyu stars such as Lee Min-ho, Park Shin-hye, and Kim Woo-bin. This drama was chosen because The Heirs is one of the most popular Korean dramas of its time, both in South Korea and overseas (IBTimes, 2017). The Heirs comprises cliche formulas or tropes that are typical to Korean drama. In online Korean drama forums such as Dramabeans, Allkpop, and Soompi, The Heir is a staple in lists of romantic 
Korean dramas, showing that The Heirs is indeed widely perceived as a drama that portrays romantic behaviors. The Heirs represents a portrayal of intimate partner violence romanticism; however, at the same time serves as a representation of the romance-genre in Korean drama from both intrinsic and audience response perspectives. Given the large audiences in South Korea and Indonesia, and the portrayal of intimate relationships, it is important this portrayal be carefully analyzed.

Korean dramas have a large audience in Indonesia and moreover, are extensively reviewed, shared, and have been adapted to Indonesian popular culture including soap opera or sinetron.Looking at audiovisual contents in Indonesian productions, there are several films which depict a romanticization of abuse, including Possessive (2017) and Dilan 1990 (2018). However, due to different socio-cultural backgrounds in Indonesia, not many scenes can be classified into particular types of intimate partner violence, such as sexual violence. Through the romanticization of abusive behavior is depicted as the male lead character's fight for love in chasing the female lead character. This depiction perpetuates violence normalization in an intimate partner relationship. This romanticization of abusive behavior is analyzed in The Heirs (2013) Korean drama, which acts as a medium of popular romance content.

The aim of this study is to examine The Heirs in romanticizing abusive behavior. It uses a narrative analysis to see how the film portrays intimate partner violence romanticism to its media audience.

\section{METHODS}

The method uses a narrative analysis, which combines a thematic and structural approach to examine characters inside the object narration. Korean drama is a fictional narration with episodic audiovisual content characteristic of a narrative text, such as characters, characterization, and plot. Therefore, narrative analysis enables a detailed study of romantic portrayals seen in the plot and character roles and relations between characters within scenes especially romanticized abuse. This research also obtained data from the information that showed from the media's article as a secondary data to look deeper into Indonesian audiences' context.

Two instruments of narrative analysis are used. The first one is Propp's narrative analysis suited to pinpoint the fixed functions of every character throughout the story. The second is Greimas' actantial model suited to dissect the dynamic relations and functions of different characters in different scenes.
The study uses four types of abusive behavior in intimate partner violence to decide scenes to be analyzed further in accordance with the purposive sampling technique.

Table 1. Intimate Partner Violence Identification (WHO, 2012)

\begin{tabular}{|l|l|}
\hline $\begin{array}{l}\text { Types of } \\
\text { Intimate Partner } \\
\text { Violence }\end{array}$ & Codes \\
\hline $\begin{array}{l}\text { Physical } \\
\text { aggression }\end{array}$ & $\begin{array}{l}\text { Aggressive grabbing, pulling, } \\
\text { slapping, hitting, kicking, beating, and } \\
\text { aggressively chasing after being rejected } \\
\text { (to have "thrill of the chase") }\end{array}$ \\
\hline Sexual coercion & $\begin{array}{l}\text { Unwanted sexual advances forced } \\
\text { kissing and forced sexual activity }\end{array}$ \\
\hline $\begin{array}{l}\text { Psychological } \\
\text { abuse }\end{array}$ & $\begin{array}{l}\text { Emotional violence, manipulating, } \\
\text { causing fear or discomfort to assert } \\
\text { dominance and power }\end{array}$ \\
\hline $\begin{array}{l}\text { Controlling } \\
\text { behaviors }\end{array}$ & $\begin{array}{l}\text { Dominating decision-making process, } \\
\text { isolating from peers, stalking, distrusting }\end{array}$ \\
\hline
\end{tabular}

With this mapping of behaviors, the romanticization of abuse in The Heirs can be identified. Character roles in The Heirs are formulated according to Propp's seven spheres of action model. Relations between each character in the specific scenes are determined through Greimas' actantial model, followed by comparing the two results to see how the characters in the locations classified as depicting abusive traits have character functions that indicate romanticization of abuse.

Propp's seven spheres of action claim a classification for characters in a narration, where each character has a function in the storyline.

Table 2. Characters in Propp Narrative (Propp, 1968)

\begin{tabular}{|l|l|}
\hline Character & Description \\
\hline Hero & $\begin{array}{l}\text { Lead the narrative, seek something or carry } \\
\text { out a mission }\end{array}$ \\
\hline Villain & $\begin{array}{l}\text { Disrupt the narrative, be against the hero } \\
\text { and morally evil }\end{array}$ \\
\hline Donor & Give something that helps the hero \\
\hline Helper & Support the hero and provide guidance \\
\hline Princess & $\begin{array}{l}\text { An object or reward sought by the hero, the } \\
\text { victim of the villain }\end{array}$ \\
\hline $\begin{array}{l}\text { Father of } \\
\text { princess }\end{array}$ & Give challenging tasks to the hero \\
\hline Dispatcher & Send the hero on a task or mission \\
\hline False Hero & Pretend to be the hero \\
\hline
\end{tabular}


Greimas adapted Propp's model and reformulated the seven characters into six actants and three actant pairs, namely: (1) subject versus object, with relations defined as the axis of desire; (2) sender versus receiver, with relations defined as the axis of transmission; and (3) helper versus an opponent, with relations defined as the axis of power.

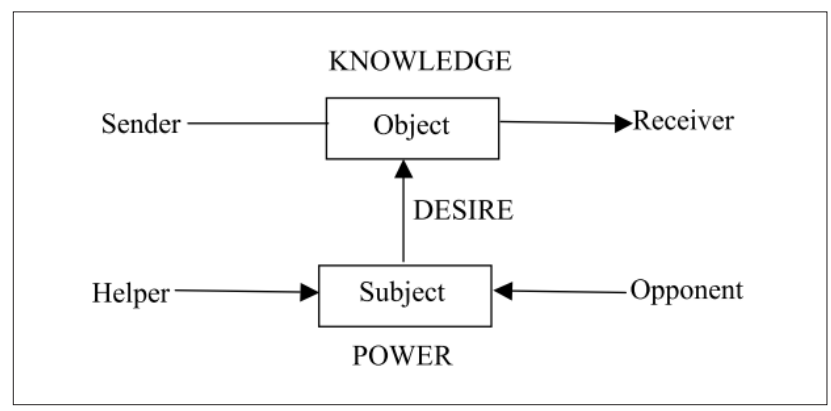

Figure 1. Greimas' Actantial Model (MA Narrative Environments, 2018)

\section{FINDINGS AND DISCUSSION}

\section{The Heirs Korean drama narrative}

The Heirs drama is set in a high school for the rich and privileged. It consists of twenty episodes, whose characters have particular function and characteristics to serve the whole narrative. One of the main characters is Kim Tan (played by worldwide Hallyu star Lee MinHo) as the male protagonist, a rich and handsome 18 year-old who is conflicted and has a problematic family. He is fascinated with Cha Eun-Sang (played by Park Shin-Hye). He fights for Cha Eun-sang's love without acknowledging her contrasting background or her initial rejections, to the point that he rebels against his social status and authoritarian father, Chairman Kim, to be with her. Cha Eun-sang is the female protagonist with a humble background. She goes to the privileged Jeguk High School thanks to Chairman Kim's social service scholarship. She's compassionate and strong-willed in some moments but cannot stand up for herself most of the time. Choi Young-do (Kim Woo-bin) is the second male lead character who's part of a love triangle with the two protagonists. He hates Kim Tan and bullies Cha Eun-sang into liking him.

The plot of The Heirs can be divided into four stages. The first stage is Kim Tan and Cha Eun-sang's initial encounters in America over episodes 1-5. The second stage is their move to Jeguk High and the beginning of conflict with other characters in episodes
6-10. The third stage is the early phase of Eun-sang and Tan's romantic relationship in episodes 11-15. The final stage is the testing of the main couple's relationship because of Chairman Kim's disagreement.

\section{Propp's seven spheres of action analysis}

The number of characters within the Korean drama The Heirs is nineteen (19) and can be divided into two main scopes; the Jeguk High students and the family.

\begin{tabular}{|c|c|c|}
\hline Scope & Character & Description \\
\hline \multirow{10}{*}{$\begin{array}{l}\text { Jeguk } \\
\text { High } \\
\text { students }\end{array}$} & Kim Tan & $\begin{array}{l}\text { Second son \& heir of Jeguk } \\
\text { Group }\end{array}$ \\
\hline & Cha Eun-sang & $\begin{array}{l}\text { New scholarship student in } \\
\text { Jeguk High }\end{array}$ \\
\hline & Choi Young-do & $\begin{array}{l}\text { Enemy of Kim Tan, likes Cha } \\
\text { Eun-sang }\end{array}$ \\
\hline & Rachel Yoo & Fiancee of Tan \\
\hline & $\begin{array}{l}\text { Yoon Chan- } \\
\text { young }\end{array}$ & $\begin{array}{l}\text { Best friend of Cha Eun-sang and } \\
\text { boyfriend of Lee Bo-na }\end{array}$ \\
\hline & Lee Bo-na & $\begin{array}{l}\text { Friend of Cha Eun-sang and } \\
\text { girlfriend of Yoon Chan-young }\end{array}$ \\
\hline & Lee Hyo-shin & $\begin{array}{l}\text { Senior and close friend of Tan, } \\
\text { Eun-sang, and Bo-na }\end{array}$ \\
\hline & Jo Myung-soo & Friend of Young-do and Bo-na \\
\hline & Kang Ye-sol & $\begin{array}{l}\text { Friend of Lee Bo-na, often } \\
\text { bullies Eun-sang }\end{array}$ \\
\hline & $\begin{array}{l}\text { Moon Joon- } \\
\text { young }\end{array}$ & $\begin{array}{l}\text { Another scholarship student } \\
\text { and victim of Choi Young-do's } \\
\text { bullying }\end{array}$ \\
\hline \multirow{9}{*}{ Family } & Kim Won & $\begin{array}{l}\text { Half brother of Kim Tan and heir } \\
\text { of Jeguk Group }\end{array}$ \\
\hline & Park Hee-Nam & $\begin{array}{l}\text { Cha Eun-sang's mute mother and } \\
\text { Kim family's housemaid }\end{array}$ \\
\hline & Madam Han & $\begin{array}{l}\text { Mistress of Chairman Kim and } \\
\text { birth mother of Kim Tan }\end{array}$ \\
\hline & Chairman Kim & $\begin{array}{l}\text { Chairman of Jeguk Group and } \\
\text { father of Kim Tan }\end{array}$ \\
\hline & Jung Ji-sook & $\begin{array}{l}\text { Stepmother of Kim Tan and } \\
\text { Chairman Kim's legal wife }\end{array}$ \\
\hline & Jeon Hyun-joo & Secret lover of Kim Won \\
\hline & Esther Lee & Mother of Rachel Yoo \\
\hline & Secretary Yoon & $\begin{array}{l}\text { Jeguk Group secretary and father } \\
\text { of Yoon Chan-young }\end{array}$ \\
\hline & $\begin{array}{l}\text { Choi Dong- } \\
\text { wook }\end{array}$ & Father of Choi Young-do \\
\hline
\end{tabular}


The overall character analysis of the Korean drama The Heirs, using Propp's seven spheres of action, is shown in Table 4.

Table 4. Analysis using Propp's seven spheres of action in The Heirs

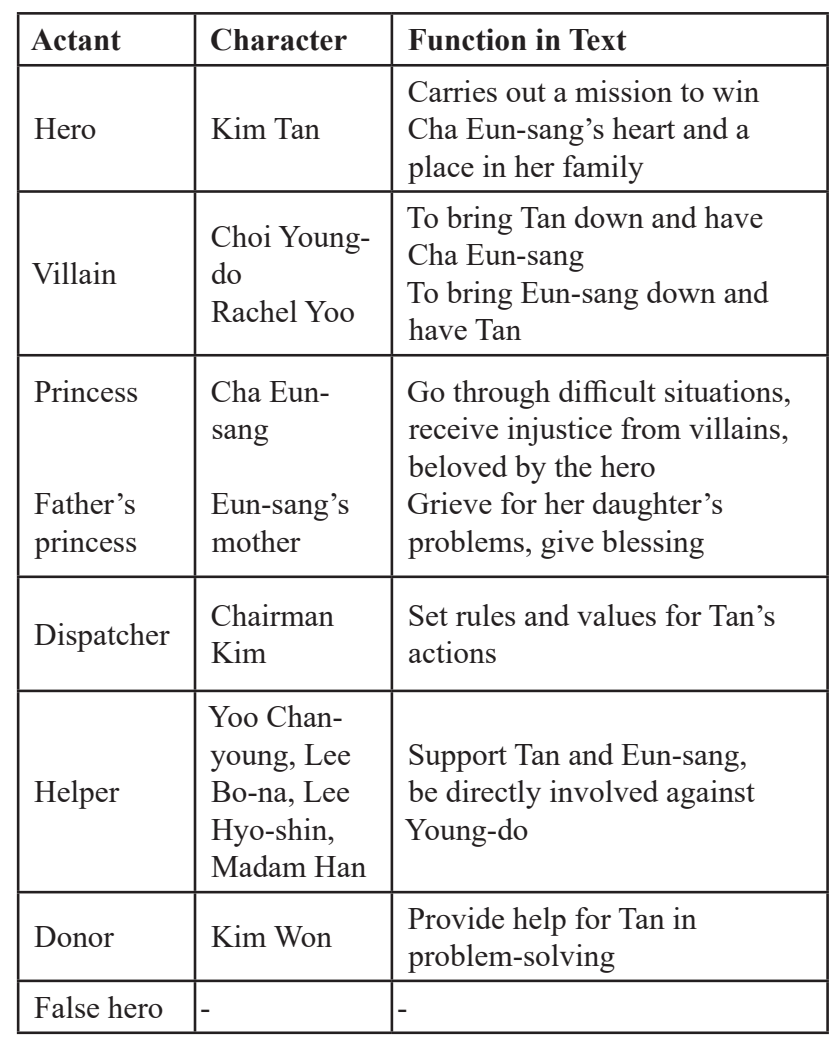

From Table 4, it can be seen that several characters carry out certain character functions for the entire narrative. The identity and role of each character depicts the narrator's intention, which is to tell a light romantic story about how Kim Tan struggles with the functions of the hero character in fighting for Cha Eun-sang as the female character. With other character implementers from villain, sender, helper, and donor, the whole plot of The Heirs manages to add to the complexity of a simple Cinderella story so that the audience remains interested in watching the twists and turns of events.

The definition (below) of an intimate partner is used to examine the romantic depiction of intimate partner violence in the drama The Heirs. Its definition is two people in a close personal relationship, which can be characterized by an emotional connection in a romantic context, regular contact, constant physical contact and/ or sexual behavior, identity as boyfriends and familiar relationships, and also knowledge of each other's lives (European Institute for Gender Equality, 2016). Intimate partner relationships are the main focus in the drama The Heirs. The resulting analysis can be mapped using the seven Propp characters in particular, the relationship between Kim Tan and Cha Eun-sang. In addition, there are many other intimate partner relationships between supporting characters including: Tan and his ex-fiancée Rachel; Young-do and his first love Eun-sang; ChanYoung and Bo-na; Director Kim and Madam Han, and Kim Won and his mistress Jeon Hyun-Joo. While the analysis using the seven Propp of the characters above does not change as the story develops, it does not accommodate character changes as the plot unfolds and accompanying role changes for Choi Young-do, Kim Won, Director Kim and others. Further analysis shows the character dynamics in The Heirs, where Tan becomes a "hero" which is better than Young-do's function as a "villain" so that the audience sympathizes with and believes Tan's character to be the best. Eun-sang as the "princess." Nonetheless, the identification of intimate partner violence proves that Tan is a flawed "hero" for the "princess" because with his romantic feelings complicates the life of Eun-sang's character, who at first insisted on not wanting to be "saved."

\section{Intimate partner violence in The Heirs}

The intimate partners in The Heirs who are the object of this study are Kim Tan and Cha Eun-sang, its the two main characters. However, their love relationship becomes a part of a love triangle with Choi Young-do also competing for Eun-sang's affections. Therefore, the scenes identified as containing intimate partner violence in the twenty episodes of The Heirs drama show the dynamics between Tan, Eun-sang, and Young-do, and Rachel Yoo as Tan's fiancée in one scene. As shown in Figure 2, in the twenty episodes of The Heirs, there are sixteen scenes depicting violent intimate partner behavior. Intimate partner violence identified in the romanc ebetween the main characters in this drama includes four categories of intimate partner violence namely, physical violence, sexual violence, psychological violence, and controlling behavior. The form of physical violence (physical aggression) that were studied were: a) the behavior of taking, pulling or pushing the partner's body aggressively, especially by grabbing the wrists and shoulders. This behavior is carried out by Kim Tan (see scene numbers 5, 8, 9, 10, and 12 in Figure 2 above) and Choi Young-do (scene number 12) to the nature Cha Eunsang character Rachel. Yoo (scene no. 3); b). Physical violence by Tan in the form of grabbing Eun-sang's arm to forcibly restrain her in scene number 13, and; c). Physical violence shown Young-do controlling Eun-sang is found 

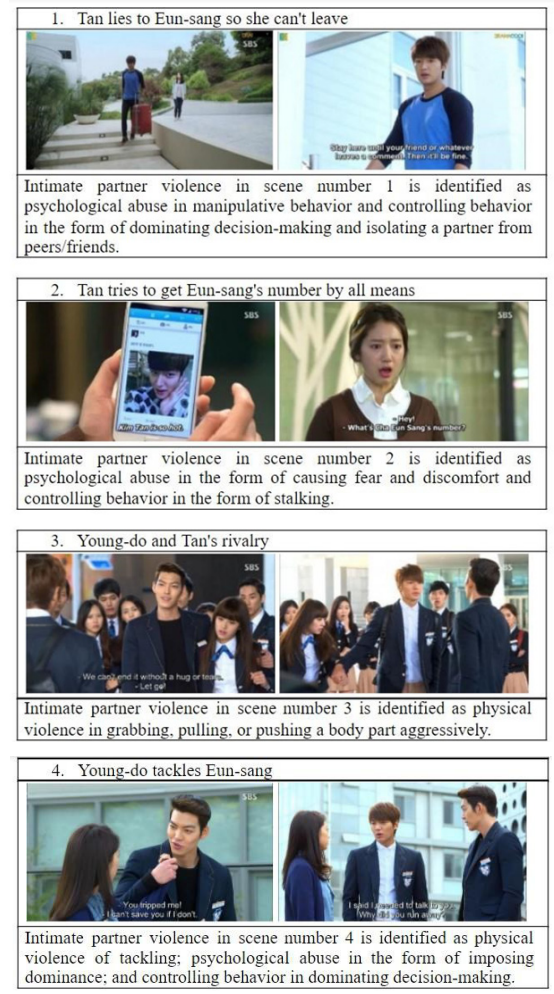

dominance; and controlling behavior in dominating decision-making.

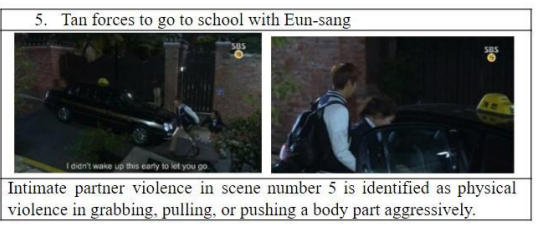

6. Tan orders Eun-sang to like him

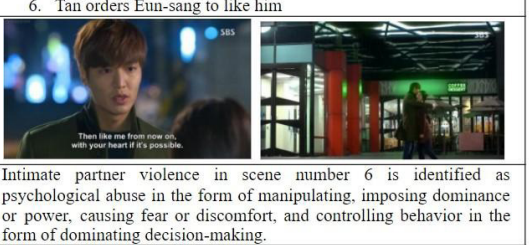

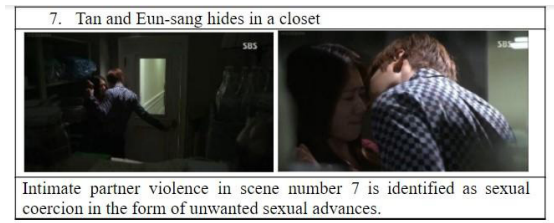

coercion in the form of unwanted sexual advances.

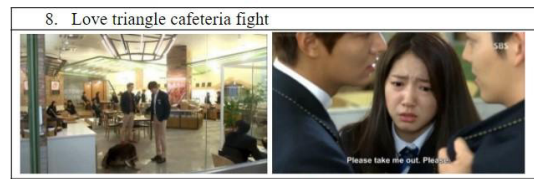

Intimate partner violence in scene number 8 is identified as physical violence in tackling and grabbing, pulling, or pushing a body part aggressively.

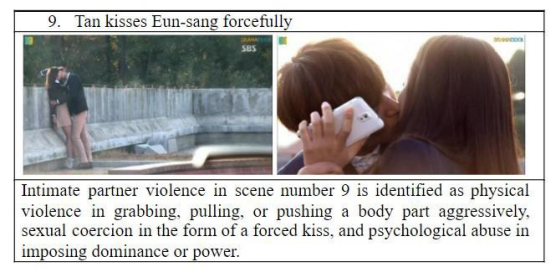

10. Tan waits for Eun-sang and confronts her

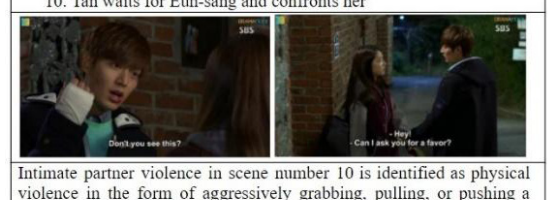

violence in the form of aggressively grabbing, pulling, or pushing a body part; and psychological abuse in imposing dominance or power.
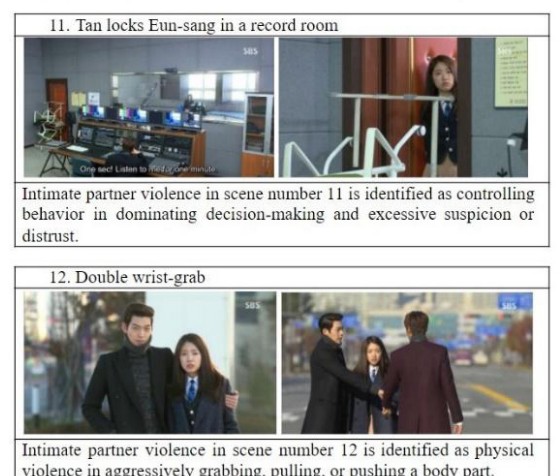
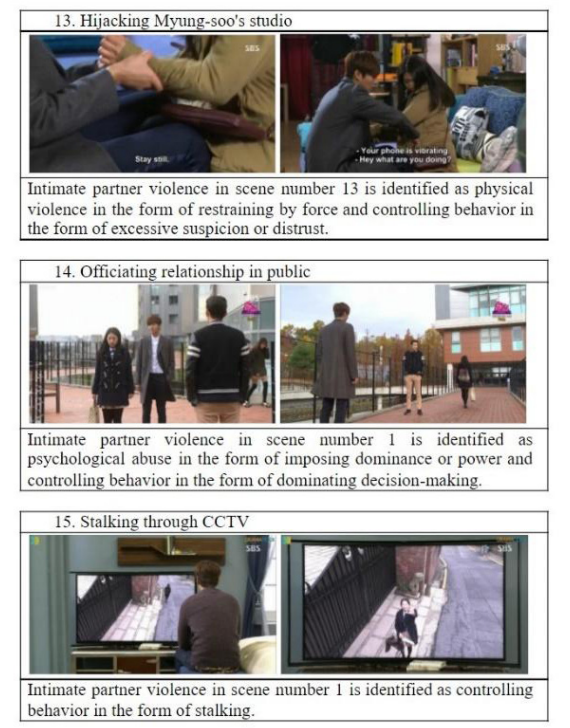

behavior in the form of stalking.

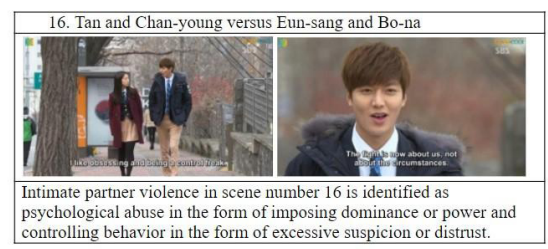

Figure 2. The Heirs scenes identified as depicting abusive behavior in scene numbers 4 and 8 . In addition to these scenes, the drama The Heirs portrays further violent behavior, especially drawing hands.

Sexually violent behavior (sexual coercion) in intimate partner relationships that can be identified in this drama are: a) unwanted sexual advances, and b) forced kisses. Eun-sang was subject to both types of sexual violence by Tan, found in a scenes numbers 7 and 9 .

The form of psychological abuse in intimate partner relationships identified in this drama was carried out by Tan against Eun-sang, which includes: a) manipulative behavior (scene numbers 1, 6, and 10), in which Tan manipulates Eun-sang's emotions by portraying himself as a victim so that Eun-sang will comply with his wishes, and b) impose power domination (scene numbers 4,6 ,
9, 14, and 16). Tan displays behavior that deliberately establishes authority or power to force his will upon Eunsang including her goals, and c) cause fear or discomfort (scene numbers 2 and 6), in which Tan insists on doing what he wants to Eun-sang even though Eun-sang has clearly stated her refusal.

The forms of controlling behavior in intimate partner relationships that can be identified are a) dominating behavior in decision making (scene numbers 1, 4, 6, 11, and 14) where Tan's coercive decisions affects Eun-sang; b) isolating from colleagues/friends (scene number 1) Tan deliberately prevents Eun-sang from being able to meet her best friend; c) stalking (scene numbers 2 and 15). These scenes depict Tan following and spying on Eun-sang, and d) excessive suspicion (scene numbers 
11, 13, and 16), in which Tan shows excessive jealousy towards whatever Eun-sang does with other men.

\section{Greimas actant relationship model Analysis}

The axis of desire from subject to object in these selected sixteen scenes always features Tan or Youngdo as subjects and Eun sang as the object of desire. The scenes involving Tan and Young-do show that they are actively doing something to achieve the object of their desire, which they like romantically. In the transmission axis, the sender is identified from the subject's actions, following specific orders, rules, or values to reach the object (Eriyanto, 2013). An external or internal matter for the subjects (Tan or Young-do) is formed, which is then projected onto the object in the form of a desire related to Eun-sang. The thing in the form of this wish reaches the recipient, namely Eun-sang, as the party who receives the consequences or benefits of the action taken by the subject (Eriyanto, 2013). Meanwhile, in the axis of power, the issue gets support from supporters while facing obstacles. The analysis using the Seven Propp characters explains the relationship between the hero and villain.

From the Greimas analysis of the relationships between the actors above, it can be found that most of the senders and objects that encourage the subjects' (Tan or Young-do) acts are directly related to their feelings for Eun-sang. However, not a few senders and things indicate Tan's and Young-do's motivation is a contest of male egos in a competitive relationship to defeat the other.

However, almost all scenes containing intimate partner violence show Eun-sang as the one who bears the consequences from the treatment of the two subjects often driven by personal egos. The depiction of these scenes makes it look romantic because it is depicted as a contest for the love of the "princess" character or Eunsang, justified as being Tan's and Young-do's feelings for Eung-sang. Packaging these scenes also indicates the glorification of the male ego in The Heirs, which results in Eun-sang becoming the victim. Eun-sang's character is not empowered to present a point of view in the settings studied hence making her the subject. This act shows how the plot of The Heirs essentially allows the "hero" and "villain" characters, Tan and Young-do, to act aggressively and proactively.

\section{Romanticization of violent behavior in The Heirs}

This analysis of the romanticization of violent behavior in Korean drama The Heirs shows aa complex reality that often appears in other romance-themed audiovisual media, where romantic relationships and violent (abusive) behavior can merge. To understand its complexity, Algirdas Greimas's concept of quadrilateral opposition, was used to map it. Through this model, almost all possible reality and its oppositions can be described and explained because it includes the complexity of reality as a whole (Eriyanto, 2013).

The romantic depiction of intimate partner violence in The Heirs refers to the contradiction between romantic relationship narratives and violent (abusive) behavior. In this study, two narrative propositions are found in relationships between characters, their romantic relationships and violent behavior, which can then be reduced to two others in the form of non-abusive behavior and unromantic relationships. These contrasting narratives can be seen scattered throughout the drama.

In the Greimas quadrilateral opposition analysis of the Korean drama The Heirs, the four axes consist of: a) a positive deixis on one axis showing a combination of romantic relationships and non-abusive behavior. In The Heirs, this reality is found in the intimate relationship between Yoon Chan-young and Lee Bo-na; b). the negative deixis on another axis indicating a combination of abusive behavior and an unromantic relationship. In The Heirs, this is found in Kim Tan's and Choi Youngdo's hostile relationship c). the neutral axis shows a natural pairing of unromantic relationships with nonabusive behavior. This neutral aspect can be seen in the in the friendship of Yoon Cha-young and Cha Eun-sang; d). the complex axis shows a combination of romantic relationships in which violent intimate partner behavior occurs, which is described as more romantic than the reality, seen in Kim Tan and Cha Eun-sangs relationship.

The romanticization of violent behavior mapped on the complex axis shows an oppositional relationship between the two narrative propositions. Previous research shows that if there is a high level of agreement that a relationship in audiovisual content is romantic, then the level of understanding that the relationship is abusive or violent becomes low, and vice versa (Timmons, 2015). This oppositional relationship is reflected in the romantic portrayal of intimate partner violence in The Heirs, where what should appear to be violence becomes distorted as romanticism.

Intimate partner violence identified in the Korean drama The Heirs is presented as romantic behavior based on the male lead's love for the female lead. The actions between those two are studied in terms of a romanticizing of violent behavior, which means violent behavior in a 
love relationship is portrayed as unrealistic, idealized, more romantic, or attractive than reality (Salmi, 2014' Segrin \& Nabi, 2002). The Heirs goes beyond the normalization of violence and the romanticization of love by depicting violence as romance. The romanticization of violent behavior is achieved by defining Kim Tan as a "hero" and a subject and Cha Eun-sang's character as a "daughter" and object. These findings reinforce a narrative of The Heirs as Cinderella story; a princess is chased and changed by a hero. Its romanticized narrative became the attraction, making it saleable and famous as a Korean drama in the romantic genre.

Korean dramas had penetrated the Indonesian market since the 2000s, when Autumn in My Heart (2000) was first aired on a local television station in 2001, followed by Winter Sonata (2002), Jewel in the Palace (2003), and Full House (2004) on several Indonesian private television stations (Uzone. id, 2019). Due to this proven popularity, Indonesian audiovisual content producers created soap operas that adapted storylines from famous Korean dramas. These include Demi Cinta (2005) that was adapted from Autumn in My Heart, Benci Bilang Cinta (2006-2007) that was adapted from Princess Hours (2006), and Kejora dan Bintang (2009-2010) that was adapted from Brilliant Legacy (2009) (Akurat.co, 2019). These adaptations further consolidate the position of Korean drama in the romance genre for its Indonesian audience. Indonesian mass media websites were found to include The Heirs in their lists of recommendations, such as "11 recommended romantic Korean dramas in 2013-2018" (IDN Times, 2019), "7 Korean dramas cute and emotional love triangle" (Kompas.com, 2020), and even included in an article of recommended best Korean dramas of all time posted by a website specifically for young Indonesian women (HaiGadis.com, 2019). Thus, it shows how the portrayal of the romanticization of abuse in The Heirs affects the Indonesian audience.

The study of The Heirs above relates to the concepts previously reviewed. The idea of fictional framing explains that the romantic framing of Tan and Young-do's violent behavior towards Eun-sang in such

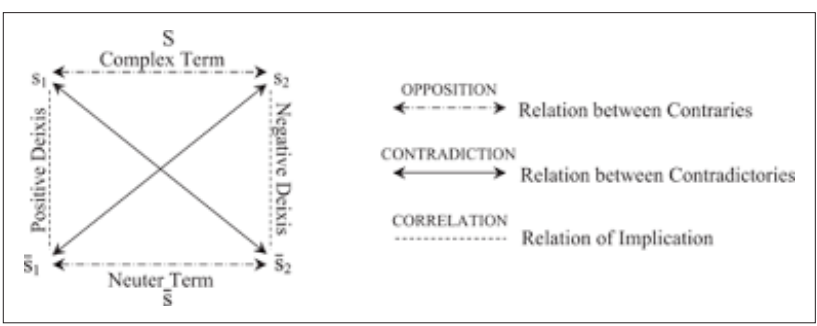

Figure 2. Greimas quadrilateral opposition (Pelkey, 2016) a way can influence the opinions and perceptions of the audience towards forms of violence that are normalized or idealized as a form of love. In contrast, the social construction of reality theory explains the projection of Tan and Tan's violent behavior. Young-do can form or maintain a reality construction related to a social understanding of the form of love that is agreed upon as romantic. As is well known, audiovisual content as mass media shapes and reflects social life (Galician, 2004). Therefore, the depiction of violent behavior as romance in the Korean drama The Heirs distorts the reality, where intimate partner violence is desensitized, justified, and romanticized.

Not only does this narrative contradict the antisexual violence slogan "No Means No", but it also promotes the opposite of an appropriate and non-violent love relationship. There are two possibilities should the drama The Heirs have been reworked to depict the romanticism of a healthy intimate partner, namely: a) Tan appreciates Eun-sang's refusal, or b) Eun-sang plays a role in initiating and forming an intimate partner relationship with Tan based on consent. Both parties voluntarily show mutual interest, respect each other's decisions, and support each other without coercion. This narrative promotes healthy intimate partner relationships instead of fetishizing rejection by perpetuating a story that the female characters rejects outright. The male character forces his will.

Such media representations can keep survivors from recognizing or avoiding, or leaving an abusive relationship rather than questioning it (Zgodinski, 2017 \& Béres, 1999). In Indonesian society, violence in dating relationships is rife because love is still seen as ownership. Indonesian culture, in general, considers that violence only occurs when there is a physical crime. In contrast, possessiveness, extreme jealousy, stalking, and regulating behavior are regarded as expressions of affection (Amiruddin in Asmarani, 2015). As mentioned in the literature review section, there are some Indonesian movies highlighting normalized violence besides Dilan 1990 (2018). It has existed since the 1970s, such as in the films Berandal-berandal Metropolitan (1971) and Ali Topan Anak Jalanan (1974) that emphasized the narrative of the bad boy who makes the good girl interested in him (Dewi, 2018).

The findings of this study emphasize that the construction of reality reflected in and framed by the media shows that violent behavior towards intimate partners can be normalized by being romanticized so that perpetrators and survivors of abusive relationships can justify violence as a form of love. 


\section{CONCLUSION}

The Heirs was found to romanticize abusive behavior through (1) the depiction of the male main characters as acting solely to fight for their love for the female main character, then justifying their violent behavior during that time in the name of love, (2) the determination of the main male character as a subject who forces the relationship without accepting rejection, (3) the presentation of the main female character as an object who refuses advances only so as to give the male character the "thrill of the chase."

From twenty episodes, there were sixteen scenes containing intimate partner violence. These sixteen scenes also encapsulated the indicators of intimate partner violence in The Heirs as a whole. The two leading male characters, Tan and Young-do, subject the female lead, Eun-sang, and Rachel to these behaviors in one scene. The identified intimate partner violence behavior was as follows: physical aggression, sexual coercion, psychological violence, and controlling behavior.

Controlling behavior was the most prevalent type of intimate partner violence, identified in nine scenes, followed by physical violence and psychological violence, each of which was found in eight scenes. The last type of intimate partner violence, sexual violence, was identified in two scenes.

Using Greimas' relation analysis on scenes featuring violent intimate partner behavior, it was found that the two leading male characters, Tan and Youngdo, are the principal subjects, whereas Eun-sang's main female character acts as the recipient of this abuse and serves as the object.

The axis of desire linked the subject, Tan or Youngdo to their object, in the form of something they want from Eun-sang. The axis of transmission from the sender and thing to the receiver in The Heirs originated from a specific command or value driving the subject to reach the object. This was projected in the form of the subject's actions that then impacted Eun-sang as the recipient. The axis of power between issues, supporters, and inhibitors showed the relationship of the power conflicts between Tan, Young-do, and their friends on Tan and Young-do's side.

The results of the analysis using the Greimas quadrilateral opposition model to the relationship of the main character in The Heirs depicted two contradictory narrative propositions, namely romantic relationships and violent behavior. The relationship between the two main characters, Tan and Eun-sang, laid on a complex axis showing a love relationship that romanticized intimate partner violence. Because of the popularity of romance- themed Korean dramas in Indonesia, it is important to address the portrayal of the romanticization of abusive behavior. This paper consequently shows how viewers, including Indonesian ones, come to see abusive behavior in romantic relationships as acceptable, if not desirable.

\section{REFERENCES}

Eriyanto. (2013). Analisis Naratif: Dasar-Dasar dan Penerapannya dalam Analisis Teks Berita Media. Jakarta: Prenadamedia Group.

Galician, M. L. (2004). Sex, Love \& Romance in the Mass Media: Analysis \& Criticism of Unrealistic Portrayals \& Their Influence. New Jersey: Larence Erlbaum Associates.

McQuail, D. (2010). McQuail's Mass Communication Theory. London: Sage Publications.

Propp, V. (1968). Publications of the American Folklore Society: Morphology of the Folktale (2nd ed.). Texas: University of Texas Press

Ariffin, J. T., Bakar, H. A., \& Yusof, N. H. (2018). Culture in Korean Drama towards Influencing Malaysian Audiences. International Journal of Innovative Research in Engineering \& Management 5(1), 10-14.

Bachen, C. M., \& Illouz, E. (1996). Imagining romance: Young people's cultural models of romance and love. Critical Studies in Mass Communication, 13, 279307.

Béres, L. (1999). Beauty and the beast: The romanticization of abuse in popular culture. European Journal of Cultural Studies, 2, 191-207.

Dewi, N. (2020). Bagaimana Film Meromantisasi Kekerasan dalam Hubungan. Retrieved on July, $30^{\text {th }} 2021$, from https://irto.id/bagaimana-film-meromantisasikekerasan-dalam-hubungan- $24 \mathrm{c}$

Holmes, B. M. (2007). In search of my "one-andonly": romance-related media and beliefs in romantic relationship. The Electronic Journal of Communication, 17(3/4), 1-23.

Hong, Y. O., Yeon, S. J., \& Ju, S. H. (2015). Violence against Women: Focused on Intimate Partner Violence between Lovers. Retrieved from https://eng.kic.re.kr

Jin, B. \& Kim, J. (2015). Television Drama Viewing and Romantic Beliefs: Considering Parasocial Interaction and Attachment Style. International Journal of Humanities and Social Science, 5(10), 51.

Johnson, K. R. \& Holmes, B. M. (2009). Contradictory Messages: A Content Analysis of HollywoodProduced Romantic Comedy Feature Films. Communication Quarterly, 57(3), 352-373.

Pelkey, J. (2016). Greimas embodied: How kinesthetic opposition grounds the semiotic square [Image]. De Gruyter, 2017(214), 277-305. 
Segrin, C., \& Nabi, R. L. (2002). Does television viewing cultivate unrealistic expectations about marriage? Journal of Communication, 52(2), 247-263.

Salmi, A. (2014). Abusive Behavior : An analysis of Edward Cullen in Stephenie Meyer's Twilight (Dissertation). Karlstad University, Sweden.

Timmons, B. (2015). The Influence of Popular Romanticized Media on Adolescent College Students' Perceptions of Dating Relationships and Dating Violence: A Focus on the Twilight Series (Masters thesis). University of Nevada, Reno.

Zgodinski, B. R. (2017). I Hate It, But I Can’t Stop: The Romanticization of Intimate Partner Abuse in Young Adult Retellings of Wuthering Heights (Masters thesis). Cleveland State University, Ohio.

Asmarani, D. (2015). Young, in love, and abused in Indonesia. Retrieved on 21 July 2020, from https:// rappler.com/world/asia-pacific/ indonesia-womendating-marriage-relationship-abuse

European Institute for Gender Equality. (2016). Analysis of National Definitions of Intimate Partner Violence. Retrieved on 11 August 2020, from https://eige. europa.eu/sites/default/files/ documents/database/ gbv_natdefn_ipv.pdf

IBTimes. (2017). Four Years of 'Heirs', Korea's most popular drama. Retrieved on 19 January 2020, from ibtimes.sg/four-years-heirs-koreas-most-populardrama-17876

National Criminal Justice Reference Service. (2018). 2018 NCVRW Resource Guide: Intimate Partner Violence Fact Sheet. Retrieved on 18 November 2019, from https:/ovc.ncjrs.gov/ncvrw2018/ info_flyers/fact sheets/2018NCVRW_IPV_508_QC.pdf

World Health Organization. (2012). Understanding and addressing violence against women: Intimate partner violence. WHO/RHR/12.36. Retrieved on 18 November 2019, from https://apps.who.int/iris/ bitstream/handle/ 10665/77432/WHO RHR 12.36 eng.pdf;jsessionid=F68B2F6B1A5EA44520863BD $\overline{7}$ 3404BA402? sequence $=1$

World Health Organization. (2017). Violence against women. Retrieved on 18 November 2019, from https://www. who.int/news-room/fact-sheets/detail/violenceagainst-women

World Health Organization. (n.d.) Definition and typology of violence. Retrieved on 11 August 2020, from https://www.who.int/violence prevention/ approach/definition/en/\#: :text=\%22 the $\% 20$ intentional $\% 20$ use $\% 20$ of $\% 20$ physical, $\% 2 \mathrm{C} \% 20$ maldevelopment $\% 2 \mathrm{C} \% 20$ or $\% 20$ deprivation. $\% 22$ 